Article

\title{
Evaluation on the Methane Production Potential of Wood Waste Pretreated with $\mathrm{NaOH}$ and Co-Digested with Pig Manure
}

\author{
Renfei Li ${ }^{1,2}$, Wenbing Tan ${ }^{1,2}$, Xinyu Zhao ${ }^{1,2}$, Qiuling Dang ${ }^{1,2}$, Qidao Song ${ }^{3}$, Beidou Xi ${ }^{1,2, *(1)}$ \\ and Xiaohui Zhang ${ }^{1,2, *}$ \\ 1 State Key Laboratory of Environmental Criteria and Risk Assessment, Chinese Research Academy of \\ Environmental Sciences, Beijing 100012, China; lirenfei1114@163.com (R.L.); wenbingtan@126.com (W.T.); \\ zhaoxinyu1126@126.com (X.Z.); dangling819@126.com (Q.D.) \\ 2 State Environmental Protection Key Laboratory of Simulation and Control of Groundwater Pollution, \\ Chinese Research Academy of Environmental Sciences, Beijing 100012, China \\ 3 Institute of Scientific and Technical Information Catas, Chinese Academy of Tropical Agricultural Sciences, \\ Haikou 571101, China; tanliu2009@126.com \\ * Correspondence: wbtann@126.com (B.X.); baixue215@163.com (X.Z.); Tel.: +86-10-8491-3133 (B.X.)
}

Received: 8 June 2019; Accepted: 14 June 2019; Published: 17 June 2019

\begin{abstract}
Wood waste generated during the tree felling and processing is a rich, green, and renewable lignocellulosic biomass. However, an effective method to apply wood waste in anaerobic digestion is lacking. The high carbon to nitrogen $(\mathrm{C} / \mathrm{N})$ ratio and rich lignin content of wood waste are the major limiting factors for high biogas production. $\mathrm{NaOH}$ pre-treatment for lignocellulosic biomass is a promising approach to weaken the adverse effect of complex crystalline cellulosic structure on biogas production in anaerobic digestion, and the synergistic integration of lignocellulosic biomass with low $\mathrm{C} / \mathrm{N}$ ratio biomass in anaerobic digestion is a logical option to balance the excessive $\mathrm{C} / \mathrm{N}$ ratio. Here, we assessed the improvement of methane production of wood waste in anaerobic digestion by $\mathrm{NaOH}$ pretreatment, co-digestion technique, and their combination. The results showed that the methane yield of the single digestion of wood waste was increased by $38.5 \%$ after $\mathrm{NaOH}$ pretreatment compared with the untreated wood waste. The methane production of the co-digestion of wood waste and pig manure was higher than that of the single digestion of wood waste and had nonsignificant difference with the single-digestion of pig manure. The methane yield of the co-digestion of wood waste pretreated with $\mathrm{NaOH}$ and pig manure was increased by $75.8 \%$ than that of the untreated wood waste. The findings indicated that wood waste as a sustainable biomass source has considerable potential to achieve high biogas production in anaerobic digestion.
\end{abstract}

Keywords: wood waste; biofuel; lignocellulosic biomass; $\mathrm{NaOH}$ pretreatment; anaerobic co-digestion

\section{Introduction}

Wood is a natural, renewable, and recyclable green material and bioenergy source. Under the circumstance of increasing depletion of non-renewable energy and material, getting the utmost out of wood is increasingly important. In general, almost $50 \%$ of a tree can converted to the final products, and the rest remain as wood waste (WW) [1]. WW mainly consist of the residues from tree felling and processing, as well as discarded furniture and building materials [2]. Among these processes, sawmills account for $40-60 \%$ of the total WW generation $[3,4]$. The total amount of China's WW is estimated to be 30.28 million tons in 2013 [5]. However, to date, only a minority of WW can be used for recycling and reusing, and an effective method to fully utilize these solid wastes has not been developed. Currently, the main treating options for WW are incineration for heating, thermal power 
generation, and heat recovery due to its high calorific value. However, direct incineration for energy conversion is inefficient, and large amounts of greenhouse gases and volatile organic compounds can be released during the incineration, especially in small boilers or combustion chambers that often lack emission control systems. These emissions may cause serious environmental pollution.

The biofuels produced from lignocellulosic materials (e.g., wood and agricultural crops) are a green, sustainable, renewable energy, and biofuel production has become a Chinese national strategy [6]. Anaerobic digestion offers an attractive option for the utilization of WW for biogas production [7]. Nevertheless, a high carbon-to-nitrogen $(\mathrm{C} / \mathrm{N})$ ratio and high crystalline cellulosic structure make it difficult for WW to continuously and efficiently yielding biogas, which limits its large-scale application in anaerobic digestion technology [8].

Anaerobic co-digestion (AcoD) is a promising optimization technique in biogas production. This process lies in balancing the nutrients, bacterial diversity, $\mathrm{pH}$, toxic compounds, and dry matter in different substrates to achieve a yield-increasing effect of $\mathrm{CH}_{4}$ [9-11]. The methane yield of different substrates can be remarkably elevated via the AcoD technique compared with single-substrate digestion [12]. Given the ability of the intrinsic characteristics of animal manures (low $\mathrm{C} / \mathrm{N}$ ratio and high $\mathrm{NH}_{4}-\mathrm{N}$ content) to complement those of lignocellulosic biomass (high $\mathrm{C} / \mathrm{N}$ ratio and rich lignocellulosic content) in digestion, mixing animal manures and lignocellulosic biomass (e.g., wood and straw) in AcoD to achieve production improvement for the biogas yield of different substrates is a common practice. For instance, Li et al. [6] recommended applying rice straw (RS) to pig manure (PM) in a (volatile solid) VS ratio of 1:1 or 1:2 can evidently increase biomethane production.

The high crystalline cellulosic structure is a substantial factor limiting the enzymatic degradation of lignocellulosic biomass during digestion [13]. To break down the linkages between lignin monomers or between lignin and polysaccharides to obtain lignocellulosic biomass, which is readily hydrolyzed, many pretreatment approaches have been established and normally categorized into three types: chemical (i.e., alkaline, acidic, and inorganic salts), physical (i.e., microwaves and liquid hot water), and biological (enzymatic and fungal). Within the pretreatment categories, $\mathrm{NaOH}$ pretreatment has been extensively applied to optimize biogas production of a wide range of lignocellulosic biomass [14].

Considering that the successful application of WW in anaerobic digestion to produce biomethane possibly brings considerable benefits because such feedstock is an abundant, cheap, and sustainable alternative, the utilization potentiality and optimizing strategy of WW in biogas production has to be evaluated. Although some studies have investigated the performance of biogas production from wood in anaerobic digestion $[7,15,16]$, the information of the potential and optimizing strategy for WW to achieve high biogas production is still limited. For example, the optimizing strategy used for improving the biogas production of WW were scarce, and the comparisons of the improvements of biogas production between WW and conventional digestion substrates (e.g., lignocellulosic biomass and animal manure) under the same optimizing strategy, which can be used for more effectively assessing the optimization effect of biogas production of WW, were also lacking in previous studies. This study aimed to assess the performance and potential of methane production from WW in anaerobic digestion. The aim was achieved by (1) evaluating the disparity in biomethane productions between WW and the conventional digestion substrates (RS for lignocellulosic biomass and PM for animal manure), and (2) evaluating the improvement of biomethane production of WW under the effect of different optimizing strategies ( $\mathrm{NaOH}$ pretreatment, $\mathrm{AcoD}$ technique, and their combination).

\section{Results}

\subsection{Daily and Cumulative Methane Production from Different Substrates}

Figure 1 presents the daily and cumulative methane yields with time for each digestion type. The maximum daily $\mathrm{CH}_{4}$ yields of the single-substrate digestions of PM, WW, and RS were 14.2 (day 1), 17 (day 1), and $21.2 \mathrm{~mL} \mathrm{CH}_{4} / \mathrm{g}$ VS (day 2), respectively, during the $49 \mathrm{~d}$ of incubation (Figure 1a). After the production peak, the daily methane yield of WW was sharply decreased to approximately $2.6 \mathrm{~mL}$ 
$\mathrm{CH}_{4} / \mathrm{g}$ VS and then remained constant (Figure 1a). Although the overall trend of daily methane yields of PM and RS dropped observably during the single-substrate digestions, some brief rise and fall during the incubation period were also observed (Figure 1a). After the maximum production peak, the daily methane yield of PM temporarily increased at days 10 to 12,14 to 17 , and 22 to 27 . The daily methane yield of RS temporarily increased at days 10 to 15,24 to 25 , and 26 to 27 (Figure 1a). The mean cumulative methane yield of the single-digestion of $\mathrm{WW}$ was $175.81 \mathrm{~mL} \mathrm{CH}_{4} / \mathrm{g} \mathrm{VS}$, which was significantly $(p<0.05)$ lower than that of the single-digestion of PM $\left(245.09 \mathrm{~mL} \mathrm{CH}_{4} / \mathrm{g} \mathrm{VS}\right)$ and RS (252.19 $\mathrm{mL} \mathrm{CH}_{4} / \mathrm{g}$ VS) (Figure 1b). The average $\mathrm{pH}$ values of the single-digestions of WW, PS, and PM ranged from 7.5 to $8.8,6.6$ to 8.7 , and 5.5 to 8.1 , respectively (Figure 1c).
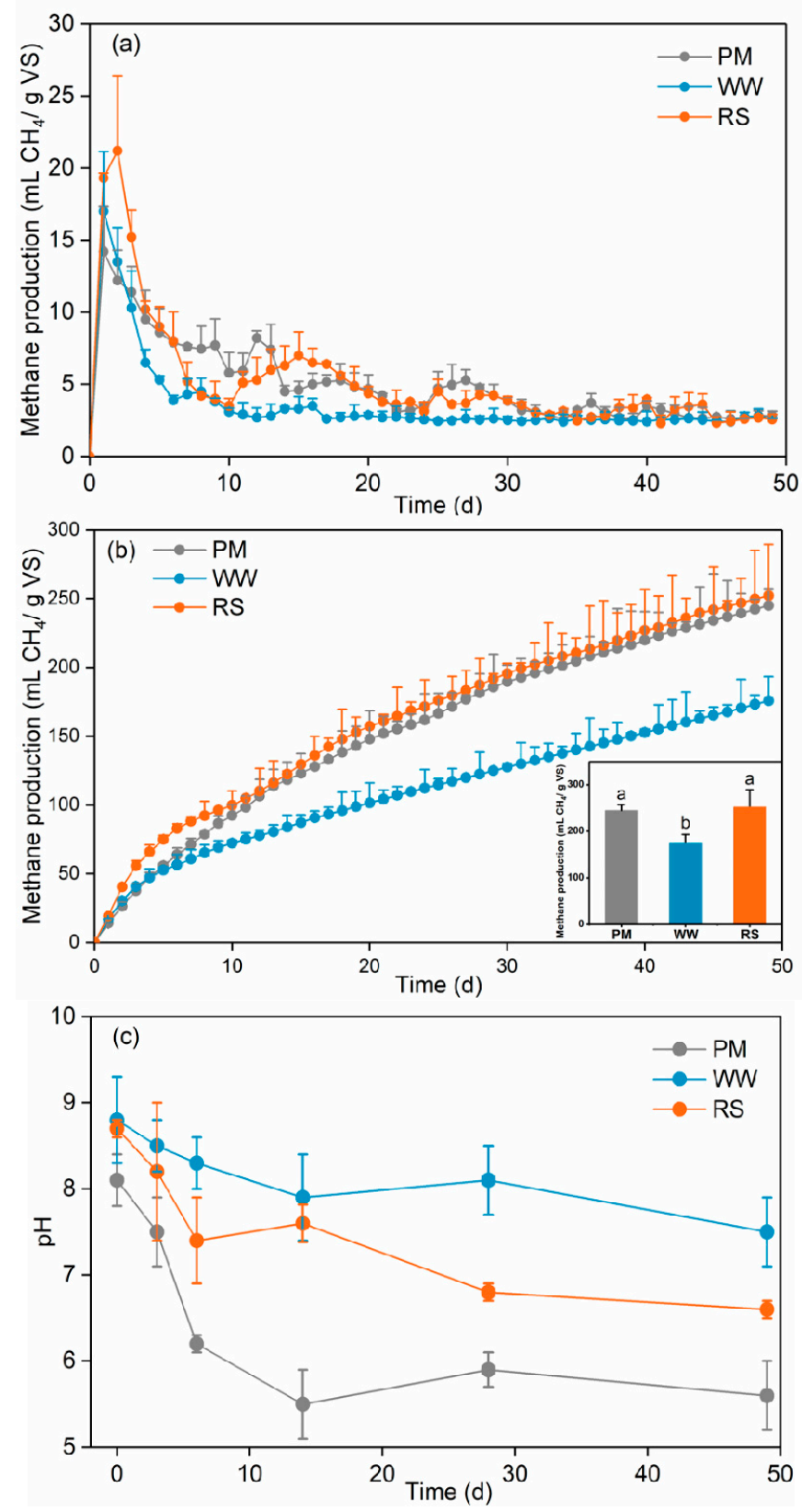

Figure 1. Daily (a) and cumulative (b) methane production and $\mathrm{pH}(\mathbf{c})$ of the single-digestions from different substrates. PM: pig manure, WW: wood waste, RS: rice straw. Different lowercase letters in the inset indicate a significant difference $(p<0.05)$ between the methane yields of different raw materials. For the calculation of methane volume, $\mathrm{P}$ and $\mathrm{T}$ was 1 standard atmospheric pressure and $25^{\circ} \mathrm{C}$, respectively. 


\subsection{Effects of $\mathrm{NaOH}$ Pretreatment on the Daily and Cumulative Methane Production from Different Substrates}

After $\mathrm{NaOH}$ pretreatment, the maximum daily methane yields of WW and RS were increased from $17 \mathrm{CH}_{4} / \mathrm{g}$ VS to $19.1 \mathrm{~mL} \mathrm{CH}_{4} / \mathrm{g}$ VS (day 2) and from $21.2 \mathrm{CH}_{4} / \mathrm{g}$ VS to $22.2 \mathrm{~mL} \mathrm{CH}_{4} / \mathrm{g}$ VS (day 2), respectively (Figure 2a,c). Two mean production peaks were observed for the daily methane yield of WW on days 2 (19.1 $\mathrm{mL} \mathrm{CH}_{4} / \mathrm{g} \mathrm{VS}$ ) and 25 (6.32 $\mathrm{mL} \mathrm{CH}_{4} / \mathrm{g}$ VS) after $\mathrm{NaOH}$ pretreatment (Figure 2a). After the maximum production peak, the daily methane yield of WW temporarily increased at days 23 to 26 (Figure 2a). Three main production peaks were observed for the daily methane yield of RS on days 2 (22.2 $\mathrm{mL} \mathrm{CH}_{4} / \mathrm{g}$ VS), 14 (7.32 $\left.\mathrm{mL} \mathrm{CH}_{4} / \mathrm{g} \mathrm{VS}\right)$, and 30 (6.78 $\left.\mathrm{mL} \mathrm{CH}_{4} / \mathrm{g} \mathrm{VS}\right)$ after $\mathrm{NaOH}$ pretreatment (Figure 2a). After the maximum production peak, the daily methane yield of WW temporarily increased at days 8 to 14 and 26 to 30 (Figure 2a). Moreover, the daily methane yields of WW and RS after pretreated with $\mathrm{NaOH}$ were significantly $(p<0.05)$ higher than that of the untreated WW and RS, respectively (Figure $2 \mathrm{a}, \mathrm{c}$ ). These results showed that $\mathrm{NaOH}$ pretreatment could evidently increase the methane production of WW and RS in the single-substrate digestion process.
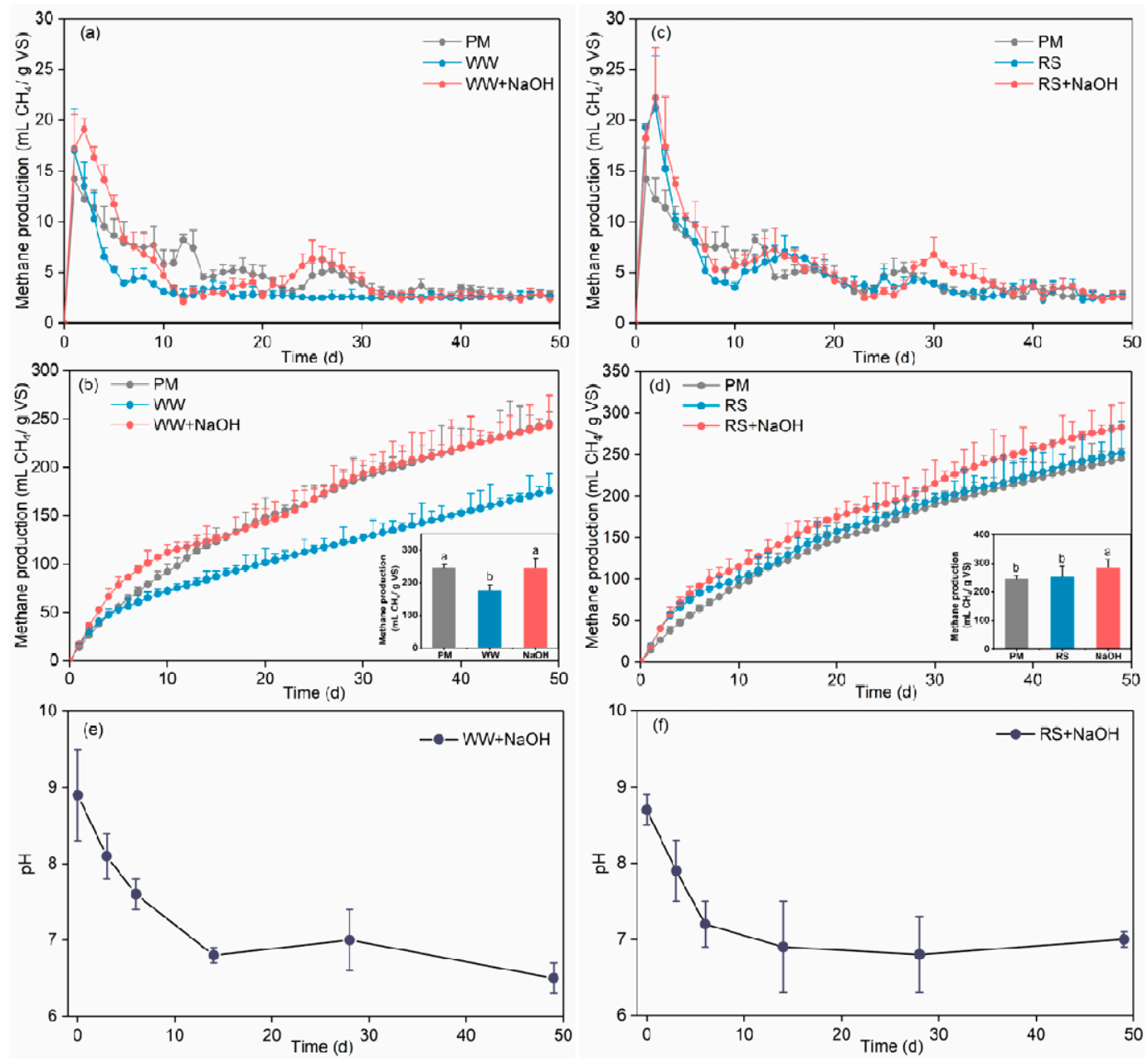

Figure 2. Daily $(\mathbf{a}, \mathbf{c})$ and cumulative $(\mathbf{b}, \mathbf{d})$ methane production and $\mathrm{pH}(\mathbf{e}, \mathbf{f})$ of the single-digestions from WW and RS before and after $\mathrm{NaOH}$ pretreatment. PM: pig manure, WW: wood waste, RS: rice straw, WW+NaOH: WW with $\mathrm{NaOH}$ pretreatment, $\mathrm{RS}+\mathrm{NaOH}$ : $\mathrm{RS}$ with $\mathrm{NaOH}$ pretreatment. Different lowercase letters in the inset indicate a significant difference $(p<0.05)$ between the methane yields of different raw materials.

The mean cumulative methane yield of the single digestion of WW was $243.53 \mathrm{~mL} \mathrm{CH}_{4} / \mathrm{g} \mathrm{VS}$ after the $\mathrm{NaOH}$ pretreatment, which nearly reached the average cumulative methane yield of the single-digestion of PM (245.09 $\mathrm{mL} \mathrm{CH}_{4} / \mathrm{g} \mathrm{VS}$ ) (Figure 2b). When pretreated with $\mathrm{NaOH}$, the mean 
cumulative methane yield of RS was increased from 252.19 to $282.94 \mathrm{~mL} \mathrm{CH}_{4} / \mathrm{g} \mathrm{VS}$ (increased by $12.2 \%$ ), which was remarkably higher than the mean cumulative methane yield of PM (Figure 2d). Moreover, the mean $\mathrm{pH}$ values of the single-digestions of WW and RS with $\mathrm{NaOH}$ pretreatment ranged from 6.5 to 8.9 and 6.8 to 8.7 , respectively (Figure 2e,f).

\subsection{Daily and Cumulative Methane Production from Different Co-Digestion Types}

Three production peaks $\left(17.8,6.21\right.$, and $\left.5.87 \mathrm{~mL} \mathrm{CH}_{4} / \mathrm{g} \mathrm{VS}\right)$ were observed for the daily methane yield of the co-digestion of WW and PM on days 1, 17, and 29 (Figure 3a). After the maximum production peak, the daily methane yield of the co-digestion of WW and PM temporarily increased at days 6 to 7,13 to 16, and 22 to 29 (Figure 3a). Four production peaks (23, 9.4, 5.75, and $6.34 \mathrm{~mL} \mathrm{CH}_{4} / \mathrm{g}$ VS) were observed for the daily methane yield of the co-digestion of RS and PM on days 2, 17, 28, and 41 (Figure 3c). After the maximum production peak, the daily methane yield of the co-digestion of RS and PM temporarily increased at days 1 to 2,11 to 17,24 to 28 , and day 37 to 41 (Figure 3c).
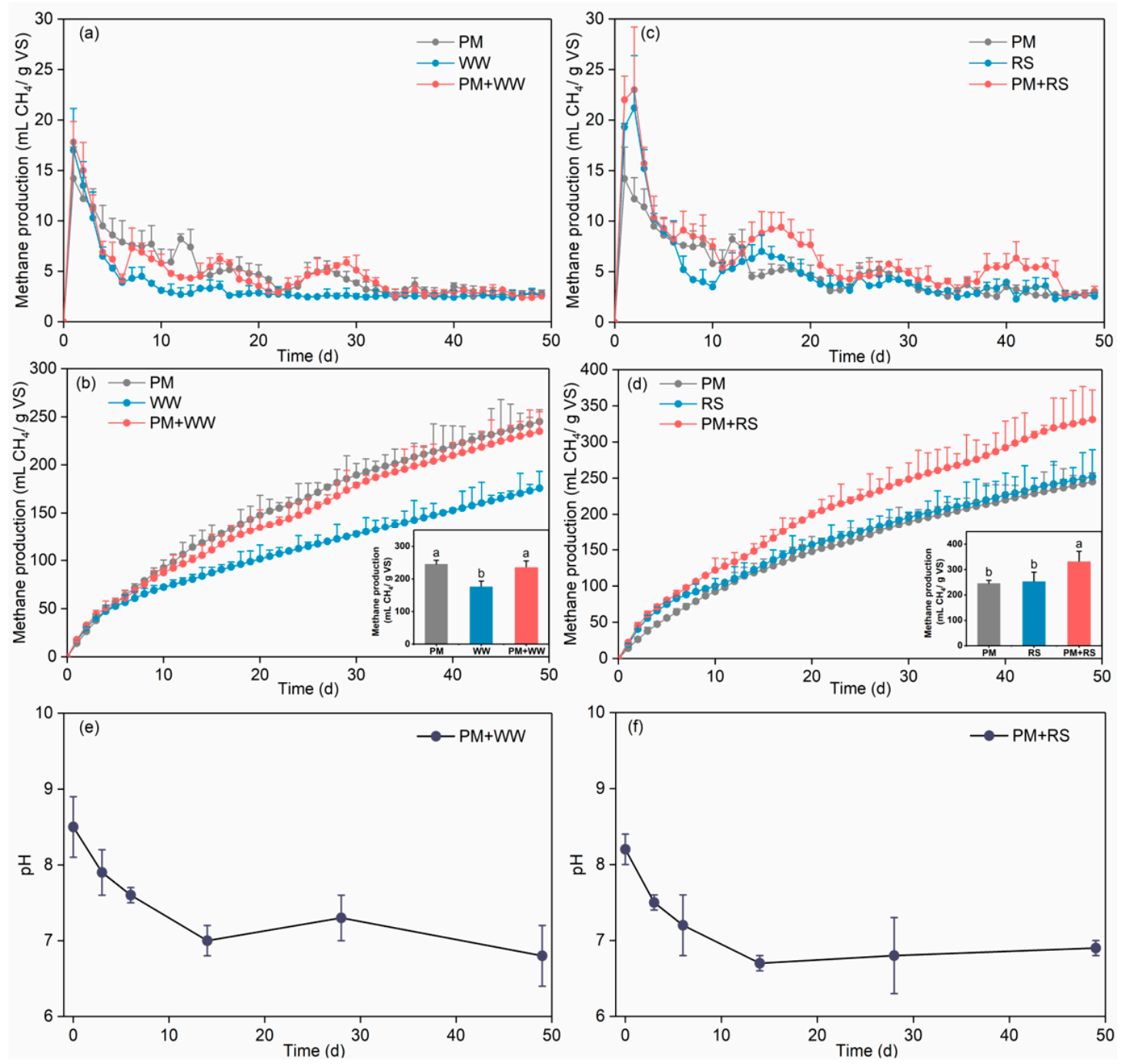

Figure 3. Daily $(\mathbf{a}, \mathbf{c})$ and cumulative $(\mathbf{b}, \mathbf{d})$ methane production and $\mathrm{pH}(\mathbf{e}, \mathbf{f})$ of the co-digestions from WW and RS with PM. PM: pig manure, WW: wood waste, RS: rice straw, PM + WW: the AcoD of PM and WW, PM + RS: the AcoD of PM and RS. Different lowercase letters in the inset indicate a significant difference $(p<0.05)$ between the methane yields of different raw materials.

The average cumulative methane yield of the co-digestion of WW and PM was $234.88 \mathrm{~mL} \mathrm{CH}_{4} / \mathrm{g}$ VS, which was increased by $33.6 \%$ compared with the single-digestion of WW (Figure 4) and nearly 
reached the mean cumulative methane yield of the single-digestion of PM (Figure 3b). As shown in Figure 3d, the cumulative methane yield of the co-digestion of RS and PM was remarkably ( $p<$ 0.05 ) higher than that of the single-digestions of both RS and PM. The average cumulative methane yield of the co-digestion of RS and PM was $331.12 \mathrm{~mL} \mathrm{CH}_{4} / \mathrm{g} \mathrm{VS}$, which was increased by $31.3 \%$ than the single-digestions of RS (Figure 4). The $\mathrm{pH}$ values of the co-digestion of PM and WW and the co-digestion of PM and RS ranged from 6.8 to 8.5 and 6.7 to 8.2, respectively (Figure 3e,f).

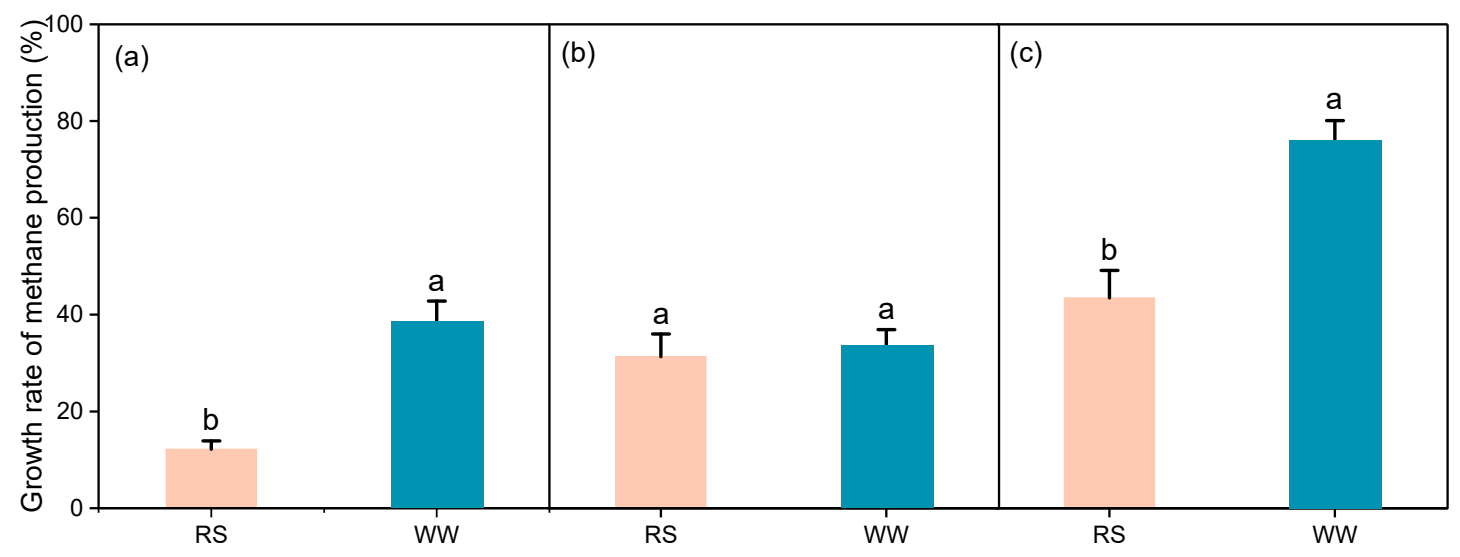

Figure 4. Growth rates of methane yield of the anaerobic digestions from WW and RS under different optimizing strategies. (a) $\mathrm{NaOH}$ pretreatment, (b) AcoD, (c) AcoD with $\mathrm{NaOH}$ pretreatment. Growth rate $=\left(\mathrm{X}_{\mathrm{T}}-\mathrm{X}_{\mathrm{O}}\right) / \mathrm{X}_{\mathrm{O}}, \mathrm{X}_{\mathrm{T}}$ denotes the mean value of biomethane yield from the treated feedstock, $\mathrm{X}_{\mathrm{O}}$ denotes the mean value of biomethane yield from the untreated feedstock. Different lowercase letters under the same optimizing strategy indicate a significant difference $(p<0.05)$ between the growth rates of methane production of different feedstocks.

\subsection{Effect of $\mathrm{NaOH}$ Pretreatment on the Daily and Cumulative Methane Production from Different Co-Digestion Types}

Three production peaks $\left(20.5,7.31\right.$, and $\left.9.11 \mathrm{~mL} \mathrm{CH}_{4} / \mathrm{g} \mathrm{VS}\right)$ were observed for the daily methane yield of the co-digestion of WW (pretreated with $\mathrm{NaOH}$ ) and PM on days 2, 17, and 28 (Figure 5a). After the maximum production peak, the daily methane yield of the co-digestion of WW (pretreated with $\mathrm{NaOH}$ ) and $\mathrm{PM}$ temporarily increased at days 1 to 2,14 to 17 , and 22 to 28 (Figure 5a). Four production peaks $\left(23.9,9.14,7.77\right.$, and $\left.6.82 \mathrm{~mL} \mathrm{CH}_{4} / \mathrm{g} \mathrm{VS}\right)$ were observed for the daily methane yield of the co-digestion of RS (pretreated with $\mathrm{NaOH}$ ) and PM on days 2, 14, 30, and 41 (Figure 5c). After the maximum production peak, the daily methane yield of the co-digestion of $\mathrm{RS}$ (pretreated with $\mathrm{NaOH}$ ) and PM temporarily increased at days 1 to 2,11 to 14,25 to 30 , and 37 to 41 (Figure 5 c).

The average cumulative methane yield of the co-digestion of WW (pretreated with $\mathrm{NaOH}$ ) and $\mathrm{PM}$ was $309.06 \mathrm{~mL} \mathrm{CH}_{4} / \mathrm{g} \mathrm{VS}$, which was increased by $75.8 \%$ compared with that of the single-digestion of WW (Figure $4 c$ ) and was remarkably $(p<0.05)$ higher than that of the single-digestion of WW (pretreated with $\mathrm{NaOH}$ ) and the co-digestion of $\mathrm{WW}$ and $\mathrm{PM}$ (Figure 5b). The average cumulative methane yield of the co-digestion of RS (pretreated with $\mathrm{NaOH}$ ) and $\mathrm{PM}$ was $361.73 \mathrm{~mL} \mathrm{CH}_{4} / \mathrm{g}$ VS, which was increased by $43.4 \%$ compared with that of the single-digestion of RS (Figure 4c) and was remarkably $(p<0.05)$ higher than that of the single-digestion of $\mathrm{RS}$ (pretreated with $\mathrm{NaOH}$ ) and the co-digestion of RS and PM (Figure 5d).The $\mathrm{pH}$ values of the co-digestion of PM and WW (pretreated with $\mathrm{NaOH}$ ) and the co-digestion of PM and $\mathrm{RS}$ (pretreated with $\mathrm{NaOH}$ ) ranged from 6.3 to 8.6 and 6.4 to 8.2 , respectively (Figure $5 \mathrm{e}, \mathrm{f}$ ). 

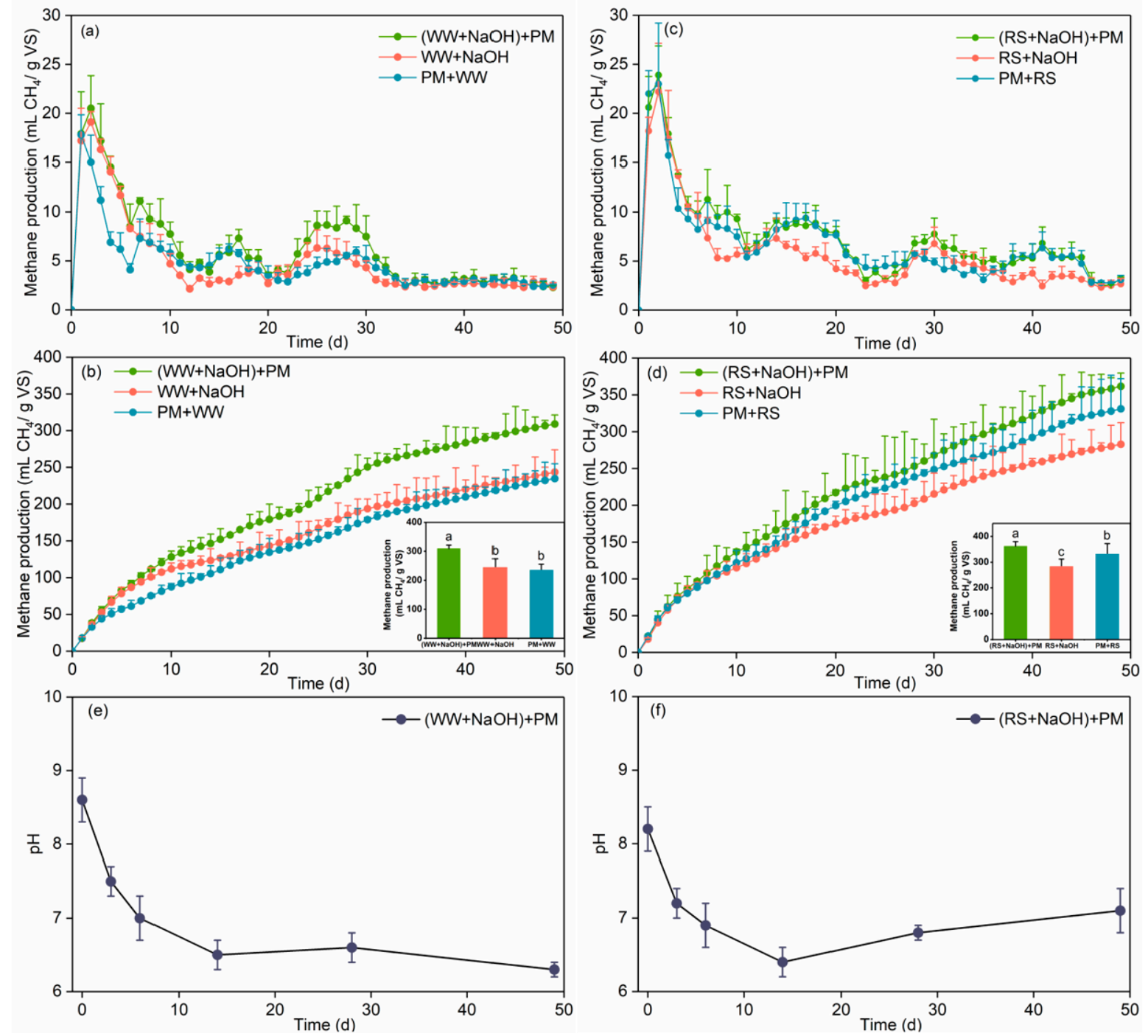

Figure 5. Daily $(\mathbf{a}, \mathbf{c})$ and cumulative $(\mathbf{b}, \mathbf{d})$ methane production and $\mathrm{pH}(\mathbf{e}, \mathbf{f})$ of the co-digestions from WW and RS with PM after pretreatment with $\mathrm{NaOH}$. WW + NaOH: WW with $\mathrm{NaOH}$ pretreatment, RS + NaOH: RS with $\mathrm{NaOH}$ pretreatment, $(\mathrm{WW}+\mathrm{NaOH})+\mathrm{PM}$ : the AcoD of PM and WW (pretreated with $\mathrm{NaOH}),(\mathrm{RS}+\mathrm{NaOH})+\mathrm{PM}$ : the AcoD of PM and RS (pretreated with $\mathrm{NaOH})$. Different lowercase letters in the inset indicate a significant difference $(p<0.05)$ between the methane yields of different raw materials.

\section{Discussion}

RS and WW belonging to lignocellulosic biomass are normally composed of three major components, namely polysaccharide cellulose and hemicellulose and the aromatic non-polysaccharide lignin. The higher the lignin content in WW, the tighter the physical structure of WW than RS (Table 1) [8]. Thus, the affinity of internal cellulose and hemicellulose of WW to hydrolase was relative weak. Maintaining the $\mathrm{pH}$ close to neutral (6.8-7.2) is preferable for methanogenesis, whereas the optimal $\mathrm{pH}$ for hydrolysis and acidogenesis is within the range of 5.5-6.5 [17,18]. At the initial stage of digestion, the accumulation of organic acids produced by hydrolysis and acidogenesis was difficult due to the low affinity of wood chips to hydrolase, thus the system $\mathrm{pH}$ cannot be lowered (Figure 1c). The high $\mathrm{pH}$ value in turn suppressed the activities of hydrolysis and acidogenesis, as well as methanogenesis of the single digestion of WW. Therefore, the methane production of RS was higher than WW during the single-substrate digestion process (Figure 1b). 
Table 1. Characteristics of WW, RS, PM and inoculum.

\begin{tabular}{ccccccc}
\hline Parameter & Inoculum & PM & WW & WW + NaOH & RS & RS + NaOH \\
\hline TS (\%) & 18.9 & $18.1 \pm 0.2$ & $96.2 \pm 0.6$ & NA & $92.5 \pm 0.5$ & NA \\
VS (\%) & 9.8 & $9.4 \pm 0.1$ & $79.8 \pm 0.6$ & NA & $84.4 \pm 0.7$ & NA \\
Cellulose (\%) & NA & $23.6 \pm 0.4$ & $39.9 \pm 0.3$ & $41.2 \pm 0.3$ & $30.3 \pm 1.2$ & $33.7 \pm 1.4$ \\
Hemicellulose & NA & $21.7 \pm 1.2$ & $36.7 \pm 1.5$ & $50.9 \pm 1.6$ & $29.2 \pm 1.5$ & $40.3 \pm 1.8$ \\
(\%) & NA & $8.4 \pm 0.1$ & $13.4 \pm 0.7$ & $3.3 \pm 0.2$ & $5.4 \pm 0.4$ & $1.24 \pm 0.2$ \\
Lignin (\%) & NA & $6.9 \pm 0.2$ & $17.8 \pm 0.3$ & NA & $15.7 \pm 0.3$ & NA \\
Ash (\%) & 32.2 & $26.2 \pm 0.3$ & $37.1 \pm 0.4$ & $39.1 \pm 0.4$ & $34.3 \pm 0.5$ & $36.4 \pm 0.4$ \\
TC (\%) & 1.4 & $1.3 \pm 0.1$ & $0.7 \pm 0.1$ & $1.4 \pm 0.1$ & $0.7 \pm 0.1$ & $1.3 \pm 0.1$ \\
TN (\%) & 23.5 & 20 & 53.5 & 27.2 & 47 & 29.1 \\
C/N & & &
\end{tabular}

Notes: NA: not analyzed; PM: pig manure, WW: wood waste, RS: rice straw. WW + NaOH: WW pretreated with $\mathrm{NaOH}, \mathrm{RS}+\mathrm{NaOH}$ : RS pretreated with $\mathrm{NaOH}$.

Salehian et al. [7] found that the yield of methane produced from pine wood pretreated with $8 \%$ $\mathrm{NaOH}\left(100{ }^{\circ} \mathrm{C}\right.$ for $\left.10 \mathrm{~min}\right)$ was increased from $65 \mathrm{~mL} \mathrm{CH}_{4} / \mathrm{g}$ VS to $178.2 \mathrm{~mL} \mathrm{CH}_{4} / \mathrm{g}$ VS after 45 days of incubation. Similarly, Mirahmadi et al. [15] observed a 50\% enhancement in methane production after the $7 \% \mathrm{NaOH}$ pretreatment $\left(100{ }^{\circ} \mathrm{C}\right.$ for $2 \mathrm{~h}$ ) of birch. Though under different conditions of alkaline pretreatment, the yield of methane in the current work of eucalyptus was also remarkably elevated from 175.81 to $243.53 \mathrm{~mL} \mathrm{CH}_{4} / \mathrm{g}$ VS after $\mathrm{NaOH}$ pretreatment (Figure 2b). The complex structures of cellulose, hemicellulose, and lignin are difficult for microorganisms to degrade [19]. The daily and cumulative methane production of the single-digestions of WW and RS was evidently increased by $\mathrm{NaOH}$ pretreatment (Figure 2). This result was because alkali can break down the ether bonds between lignin and saponified the ester bonds between hemicellulose and lignin to weaken the internal hydrogen bonds within cellulose and hemicellulose [14], thus making cellulose and hemicelluloses accessible to hydrolytic enzymes. The $\mathrm{NaOH}$ pretreatment decreased the $\mathrm{C} / \mathrm{N}$ ratio of $\mathrm{WW}$ and RS to a low level from 54.5 and 47 to 27.2 and 29.1, respectively, which was more acceptable for biodegradation over the first several days (Table 1) [20]. Notably, the improvement of methane production of the single digestion of WW (increased by $38.5 \%$ ) by $\mathrm{NaOH}$ pretreatment was significantly higher $(p<0.05)$ than that of RS (increased by 12.2\%) (Figure 4). This result might be occasioned by the following reasons. First, the $\mathrm{NaOH}$ pretreatment could increase the effective contact area between anaerobic microorganisms and substrates via reducing lignin content or breaking down lignin-hemicellulose complexes [14,21]. Therefore, WW, which contained higher amounts of lignin content than RS (Table 1) [8], had higher potential in increasing effective contact area when pretreated with $\mathrm{NaOH}$. Second, the amounts of cellulose and hemicellulose that can be used to produce methane by methanogens were more contained in WW than in RS (Table 1). Thus, the improvement of the methane yield of WW could be visible when the effective contact area between anaerobic microorganisms and cellulose and hemicellulose was increased. Finally, after $\mathrm{NaOH}$ pretreatment, the $\mathrm{pH}$ value of the single digestion of $\mathrm{WW}$ was decreased to neutral, which was preferable for methanogenesis. However, the $\mathrm{pH}$ of the single-digestion of RS was almost unchanged (Figure 2e).

Compared with the single-substrate anaerobic digestions of PM and RS, the biomethane yield of the co-digestion of PM and RS was significantly $(p<0.05)$ increased (Figure 3$)$. The methane yield of RS and PM co-digestion had increased by over 30\% than both of the PM and RS single-digestions (Figures 3 and 4). High $\mathrm{C} / \mathrm{N}$ ration and rich $\mathrm{NH}_{4}-\mathrm{N}$ content are the dominant factors limiting the methane production rates of RS and PM (Table 1), respectively [22]. Mixing PM and RS could balance the $\mathrm{C} / \mathrm{N}$ ratio (Table 2) and nutrition, as well as toxic compounds generated during the digestion [23]. The AcoD with different substrates could also stimulate the synergistic effects of microorganisms for achieving improved biogas production [24]. 
Table 2. Experimental design.

\begin{tabular}{cccc}
\hline Treatments & Raw Material & VS Ratio & C/N Ratio \\
\hline T1 & PM & & 20 \\
T2 & RS & & 47 \\
T3 & WW & & 53.5 \\
T4 & WW + NaOH & & 27.2 \\
T5 & RS + NaOH & $2: 01$ & 29.1 \\
T6 & PM/WW & $2: 01$ & 31.3 \\
T7 & PM/RS & 29 \\
T8 & PM/WW(NaOH) & $2: 01$ & 22.4 \\
T9 & PM/WW(NaOH) & $2: 01$ & 23 \\
\hline
\end{tabular}

Notes: PM/WW indicates the AcoD of PM and WW. PM/RS indicates the AcoD of PM and RS. PM $/ W W(N a O H)$ indicates the AcoD of PM and WW (pretreated with $\mathrm{NaOH}), \mathrm{PM} / \mathrm{RS}(\mathrm{NaOH})$ indicates the AcoD of PM and RS (pretreated with $\mathrm{NaOH}$ ).

Co-digestion with WW had no beneficial effect on the methane production of PM (Figure 3b), which may be ascribed to the rigid and recalcitrant lignocellulosic structure of WW. On the other hand, the methane production of the co-digestion of WW and PM had nonsignificant difference with that of the single-digestion of PM (Figure 3b), suggesting WW can be utilized as a supplementary during the PM anaerobic digestion without affecting its methane production efficiency. We showed that the WW pretreated with $\mathrm{NaOH}$ had a satisfactory methane production performance in anaerobic digestion (Figure 2a,b). The methane production of WW treated with AcoD (pretreated with $\mathrm{NaOH}$ ) was increased by $75.8 \%$ compared with the untreated WW. Furthermore, the growth rates of methane production of WW treated with $\mathrm{NaOH}$ and $\mathrm{AcoD}$ (pretreated with $\mathrm{NaOH}$ ) were signally higher than the RS that under the same optimizing strategies (Figure 4). WW is widely distributed in vast rural areas and has huge reserves. Therefore, when treated with targeted approaches, WW has a considerable potential transforming from the worthless organic waste to a promising fermentation substrate.

\section{Materials and Methods}

\subsection{Substrates and Inoculum of Anaerobic Dry Digestion}

The PM and wood chips were used as the substrate of anaerobic dry digestion. The PM was obtained from the Danzhou Pig Farm (Hainan, China) and stored in a refrigerator at $4{ }^{\circ} \mathrm{C}$ before the start of the digestion experiment. The wood chips were prepared from the branches of a eucalyptus plant. The branches were crushed to obtain a diameter of less than $6 \mathrm{~mm}$, soaked in biogas slurry, and acclimated for 1 week at room temperature. The inoculum was obtained from anaerobic activated sludge (Shunyi Biogas Plant, Beijing, China) and centrifuged at 10,000 r/min for $30 \mathrm{~min}$. Afterward, the precipitate (inoculum) of the anaerobic activated sludge was acclimated for 1 week at room temperature, and the supernatant was used to soak the wood chips and regulate the total solid content in the anaerobic dry digestion system. The physical and chemical properties of PM, wood chips, RS, and inoculum are shown in Table 1.

\subsection{Treatment Design and Incubation Experiments}

A 500-mL glass vial was used as an anaerobic dry digestion reactor in this study. Nine treatments were prepared with three replicates each (Table 2). The inoculum accounted for $40 \%$ of the digestion material based on the total solid content. The digestion system was replenished with the supernatant of the centrifuged anaerobic activated sludge to $200 \mathrm{~g}$ of the total mass, uniformly stirred, placed in an anaerobic dry digestion reactor, and sealed with butyl rubber with an aluminum collecting gas bag. Each anaerobic dry digestion was incubated for 49 days in a constant-temperature incubator at $35^{\circ} \mathrm{C}$ in the dark. 
The wood chips were chemically pretreated with $\mathrm{NaOH}$ solution. Specifically, they were separately mixed with distilled water and $\mathrm{NaOH}$ solution with a mass fraction of $2 \%$ at a solid-to-liquid ratio of 1:10, uniformly stirred, treated at $90{ }^{\circ} \mathrm{C}$ for $4 \mathrm{~h}$, rinsed with deionized water until neutral, and dried. The biogas slurry was extracted through a reflux operation every $12 \mathrm{~h}$ and injected back into the anaerobic dry digestion reactor. In this way, the biogas slurry could be evenly dispersed on the digestion substrate. The wood chips without pretreatment and no reflux operation were also used as controls.

\subsection{Sample Collection and Analysis}

The biogas generated during digestion was collected in a $3 \mathrm{~L}$ aluminum gas collecting bag. The biogas in the gas collecting bag was obtained regularly by using a $200 \mathrm{~mL}$ glass syringe every day to measure the biogas production with a gas flow meter (LMF-1, Cixi Instrument Co., Ltd., Shanghai, China). In addition, a gas sample was periodically collected using a $2 \mathrm{~mL}$ syringe for methane determinations.

Total solid (TS) and VS contents were measured in accordance with standard methods [25]. Total carbon (TC) and total nitrogen (TN) contents were determined with a high-temperature automated elemental analyzer (Vario EL cube, Langenselbold, Germany). Cellulose, hemicellulose, and lignin were observed using a semi-automatic fiber analyzer (ANKOM A200i, Longjie Instrument Equipment Co., Ltd., Shanghai, China). Methane concentrations were identified on a gas chromatograph (Agilent 6890, Santa Clara, CA, USA) equipped with a thermal conductivity detector and a flame ionization detector.

Analysis of variance (ANOVA) was performed to compare the differences in cumulative methane productions of single and co-digestions from different substrates, and the differences in the growth rates of methane production of the anaerobic digestions from WW and RS under different optimizing strategies were determined. ANOVA was conducted with SPSS 20.0 (IBM Corporation Software Group, Somers, NY, USA). Results were considered significant at $p<0.05$.

\section{Conclusions}

In this study, $\mathrm{NaOH}$ pretreatment, AcoD technique, and their combination were used to test the performance and potential of the methane production of WW in anaerobic digestion. After pretreatment with $\mathrm{NaOH}$ was administered, the mean cumulative methane yield of the single digestion of WW increased from $175.81 \mathrm{~mL} \mathrm{CH}_{4} / \mathrm{g}$ VS to $243.53 \mathrm{~mL} \mathrm{CH}_{4} / \mathrm{g} \mathrm{VS}$, which was equivalent to a $38.5 \%$ increase compared with that of untreated WW. The mean methane yield of the co-digestion of WW and PM was $234.88 \mathrm{~mL} \mathrm{CH}_{4} / \mathrm{g} \mathrm{VS}$, which was higher than that of the single digestion of WW $\left(175.81 \mathrm{~mL} \mathrm{CH}_{4} / \mathrm{g}\right.$ VS) and was not significantly different from that of the single digestion of PM $\left(245.09 \mathrm{~mL} \mathrm{CH}_{4} / \mathrm{g} \mathrm{VS}\right)$. The mean cumulative methane yield of the co-digestion of WW pretreated with $\mathrm{NaOH}$ and $\mathrm{PM}$ was $309.06 \mathrm{~mL} \mathrm{CH}_{4} / \mathrm{g} \mathrm{VS}$, which was increased by $75.8 \%$ compared with that of the untreated WW and was higher than those of the single-digestion of WW pretreated with $\mathrm{NaOH}$ and the co-digestion of WW and PM. The growth rates of the methane production of WW treated with $\mathrm{NaOH}$ and $\mathrm{AcoD}$ pretreated with $\mathrm{NaOH}$ were considerably higher than those of the RS under the same optimizing strategies. This work could provide useful insights into the development of WW as a new sustainable and efficient alternative for biogas production.

Author Contributions: X.Z. (Xiaohui Zhang) and B.X. conceived and designed the experiments; R.L. and Q.S. performed the experiments; W.T. analyzed the data with suggestions by X.Z. (Xinyu Zhao) and Q.D.; W.T. and R.L. wrote the paper; B.X. and X.Z. (Xiaohui Zhang) proofed the paper.

Funding: This research was funded by the National Key Research and Development Program of China (No. 2018YFC1900102) and the National Natural Science Foundation of China (No. 51808519).

Acknowledgments: We thank Liang Zhao for assistance in the laboratory and with data analysis.

Conflicts of Interest: The authors declare no conflicts of interest. 


\section{References}

1. Turley, D.B.; Chaudhry, Q.; Watkins, R.W.; Clark, J.H.; Deswarte, F.E.I. Chemical products from temperate forest tree species-Developing strategies for exploitation. Ind. Crop. Prod. 2006, 24, 238-243. [CrossRef]

2. Souza, A.M.; Nascimento, M.F.; Almeida, D.H.; Silva, D.A.L.; Almeida, T.H.; Christoforo, A.L.; Lahr, F.A. Wood-based composite made of wood waste and epoxy based ink-waste as adhesive: A cleaner production alternative. J. Clean. Prod. 2018, 193, 549-562. [CrossRef]

3. da Silva Vieira, R.; Lima, J.T.; Moreira da Silva, J.R.; Gherardi Hein, P.R.; Baillères, H.; Pereira Barauna, E.E. Small wooden objects using eucalypt sawmill wood waste. Bioresources 2010, 5, 1463-1472.

4. Eshun, J.F.; Potting, J.; Leemans, R. Wood waste minimization in the timber sector of Ghana: A systems approach to reduce environmental impact. J. Clean. Prod. 2012, 26, 67-78. [CrossRef]

5. Wang, H.; Zuo, X.; Wang, D.; Bi, Y. The estimation of forest residue resources in China. J. Cent. South Univ. Forest. Technol. 2017, 37, 29-38.

6. Li, D.; Liu, S.; Mi, L.; Li, Z.; Yuan, Y.; Yan, Z.; Liu, X. Effects of feedstock ratio and organic loading rate on the anaerobic mesophilic co-digestion of rice straw and pig manure. Bioresour. Technol. 2015, 187, $120-127$. [CrossRef]

7. Salehian, P.; Karimi, K.; Zilouei, H.; Jeihanipour, A. Improvement of biogas production from pine wood by alkali pretreatment. Fuel 2013, 106, 484-489. [CrossRef]

8. Paul, S.; Dutta, A. Challenges and opportunities of lignocellulosic biomass for anaerobic digestion. Resour. Conserv. Recycl. 2018, 130, 164-174. [CrossRef]

9. Jha, A.K.; Li, J.; Nies, L.; Zhang, L. Research advances in dry anaerobic digestion process of solid organic wastes. Afr. J. Biotechnol. 2011, 10, 14242-14253.

10. Borowski, S.; Kucner, M.; Czyżowska, A.; Berłowska, J. Co-digestion of poultry manure and residues from enzymatic saccharification and dewatering of sugar beet pulp. Rnew. Energy 2016, 99, 492-500. [CrossRef]

11. Wang, X.J.; Yang, G.H.; Feng, Y.Z.; Ren, G.X. Potential for biogas production from anaerobic co-digestion of dairy and chicken manure with corn stalks. Adv. Mat. Res. 2012, 347, 2484-2492. [CrossRef]

12. Wang, X.; Yang, G.; Feng, Y.; Ren, G.; Han, X. Optimizing feeding composition and carbon-nitrogen ratios for improved methane yield during anaerobic co-digestion of dairy, chicken manure and wheat straw. Bioresour. Technol. 2012, 120, 78-83. [CrossRef] [PubMed]

13. Monlau, F.; Barakat, A.; Trably, E.; Dumas, C.; Steyer, J.P.; Carrère, H. Lignocellulosic materials into biohydrogen and biomethane: Impact of structural features and pretreatment. Crit. Rev. Environ. Sci. Technol. 2013, 43, 260-322. [CrossRef]

14. Sambusiti, C.; Ficara, E.; Malpei, F.; Steyer, J.P.; Carrère, H. Benefit of sodium hydroxide pretreatment of ensiled sorghum forage on the anaerobic reactor stability and methane production. Bioresour. Technol. 2013, 144, 149-155. [CrossRef] [PubMed]

15. Mirahmadi, K.; Kabir, M.M.; Jeihanipour, A.; Karimi, K.; Taherzadeh, M. Alkaline pretreatment of spruce and birch to improve bioethanol and biogas production. Bioresources 2010, 5, 928-938.

16. Nieves, D.C.; Karimi, K.; Horváth, I.S. Improvement of biogas production from oil palm empty fruit bunches (OPEFB). Ind. Crop. Prod. 2011, 34, 1097-1101. [CrossRef]

17. Park, S.; Li, Y. Evaluation of methane production and macronutrient degradation in the anaerobic co-digestion of algae biomass residue and lipid waste. Bioresour. Technol. 2012, 111, 42-48. [CrossRef] [PubMed]

18. Lemmer, A.; Merkle, W.; Baer, K.; Graf, F. Effects of high-pressure anaerobic digestion up to 30 bar on pH-value, production kinetics and specific methane yield. Energy 2017, 138, 659-667. [CrossRef]

19. Jaffar, M.; Pang, Y.; Yuan, H.; Zou, D.; Liu, Y.; Zhu, B.; Li, X. Wheat straw pretreatment with $\mathrm{KOH}$ for enhancing biomethane production and fertilizer value in anaerobic digestion. Chin. J. Chen. Eng. 2016, 24, 404-409. [CrossRef]

20. Siddique, M.N.I.; Wahid, Z.A. Achievements and perspectives of anaerobic co-digestion: A review. J. Clean. Prod. 2018, 194, 359-371. [CrossRef]

21. Li, X.; Li, L.; Zheng, M.; Fu, G.; Lar, J.S. Anaerobic co-digestion of cattle manure with corn stover pretreated by sodium hydroxide for efficient biogas production. Energy Fuels 2009, 23, 4635-4639. [CrossRef]

22. Jantrania, A.R.; White, R.K. High-solids anaerobic fermentation of poultry manure. In Proceedings of the Fifth International Symposium on Agricultural Waste, St. Joseph, MI, USA, 16-17 December 1985; pp. 73-80. 
23. Li, Y.; Chen, Y.; Wu, J. Enhancement of methane production in anaerobic digestion process: A review. Appl. Energy 2019, 240, 120-137. [CrossRef]

24. A $\breve{g}$ dağ, O.N.; Sponza, D.T. Co-digestion of mixed industrial sludge with municipal solid wastes in anaerobic simulated landfilling bioreactors. J. Hazard. Mater. 2007, 140, 75-85. [CrossRef] [PubMed]

25. American Public Health Association (APHA). Standard Methods for the Examination of Water and Wastewater; American Public Health Association: Washington, DC, USA, 2005.

(C) 2019 by the authors. Licensee MDPI, Basel, Switzerland. This article is an open access article distributed under the terms and conditions of the Creative Commons Attribution (CC BY) license (http://creativecommons.org/licenses/by/4.0/). 